\title{
Efeito de lodo de esgoto sobre patógenos habitantes do solo e severidade de oídio da soja
}

\author{
Fabio Fernando de Araújo $^{1} \&$ Wagner Bettiol ${ }^{2}$
}

${ }^{1}$ Universidade do Oeste Paulista, Rod. Raposo Tavares, Km 572, 19067-175, Presidente Prudente, SP. E-mail: fabio@ unoeste.br. ${ }^{2}$ Embrapa Meio Ambiente, C. P. 69, 13820-000, Jaguariúna, SP. E-mail: bettiol@ cnpma.embrapa.br.

Autor para Correspondência: Wagner Bettiol (bettiol@ cnpma.embrapa.br)

Data de chegada: 15/05/2008. Aceito para publicação em: 10/03/2009

\section{RESUMO}

Araujo, F.F.; Bettiol, W. Efeito de lodo de esgoto sobre patógenos habitantes do solo e severidade de oídio da soja. Summa Phytopathologica, v.35, n.3, p.184-190, 2009

O lodo de esgoto, atendendo as exigências ambientais, apresenta potencial para disposição em solos agrícolas. Sua incorporação altera as propriedades químicas, físicas e biológicas do solo, pois é rico em macro e micronutrientes e matéria orgânica. Estas alterações podem proporcionar benefícios como aumento da disponibilidade de nutrientes às culturas, indução de supressividade a fitopatógenos habitantes do solo e de resistência às doenças da parte aérea. Por outro lado, pode influenciar negativamente o equilíbrio biológico e químico no solo, devido à presença de contaminantes. O objetivo do trabalho foi avaliar os efeitos da incorporação de lodo de esgoto ao solo sobre a severidade de oídio (Erysiphe diffusa) e na supressividade a Rhizoctonia solani e a Macrophomina phaseolina da soja (Glycine max). Para tanto, foram utilizados solos que receberam quatro aplicações (1999 a 2001) sucessivas de lodos de esgoto originários das Estações de Tratamento de Esgoto de Barueri e de Franca, SP, nas concentrações de $0,1,2,4$ e 8 vezes $(0 \mathrm{~N}$ a $8 \mathrm{~N})$ a dose de $\mathrm{N}$ recomendada para a cultura do milho. Os estudos com oídio foram realizados em casa de vegetação com inoculação natural em dois cultivos sucessivos de soja. Também foi estudado o efeito de substrato produzido com $0 \%, 2,5 \%, 5 \% 10 \%, 15 \%$ e $20 \%$ de lodo de Franca sobre a emergência de plântulas e sobre a severidade de oídio da soja em três e dois ciclos, respectivamente. Nos estudos com $R$. solani e M. phaseolina, os solos foram artificialmente infestados com os patógenos e posteriormente cultivados com soja por dois ciclos, sendo avaliado o tombamento e a severidade das doenças. A aplicação de lodo de esgoto no solo aumentou a atividade eliciadora de fitoalexinas em soja e a severidade do oídio foi inversamente proporcional às concentrações do lodo, tanto no estudo com o solo de campo, como com o substrato obtido com o lodo de Franca. A emergência das plântulas de soja, nos três cultivos, foi inversamente proporcional à concentração do lodo de Franca, sendo totalmente inibida na concentração de $20 \%$. Nos estudos com $R$. solani não foram observados efeitos da aplicação do lodo da ETE de Franca sobre o tombamento e a severidade. No primeiro cultivo a resposta ao tombamento foi quadrática para o lodo Barueri, sendo que ocorreu aumento nas concentrações de $1 \mathrm{~N}$ e $2 \mathrm{~N}$, e redução na concentração $4 N$. No segundo cultivo ocorreu aumento nos índices de tombamento de plantas em relação ao primeiro, com resposta quadrática para o lodo Barueri, mas com ponto de inflexão mínimo na concentração de $1 \mathrm{~N}$, sendo que para a concentração $8 \mathrm{~N}$ o tombamento foi semelhante à testemunha. A severidade da doença no colo das plantas manteve a mesma resposta quadrática para o lodo de Barueri nos dois cultivos, com ponto de máximo na dose $4 \mathrm{~N}$. Para $M$. phaseolina a incidência da doença foi inversamente proporcional à concentração do lodo de Franca. Dessa forma, os resultados não permitem conclusão sobre a indução de supressividade à $R$. solani e M. phaseolina.

Palavras-chave adicionais: Resíduos orgânicos, doenças da soja, atividade microbiana, Rhizoctonia solani e Macrophomina phaseolina.

\section{ABSTRACT}

Araujo, F.F.; Bettiol, W. Effect of sewage sludge in soil-borne pathogens and powdery mildew severity in soybean. Summa Phytopathologica, v.35, n.3, p.184-190, 2009

Sewage sludge, complying with environmental demands, has potential for use in agriculture. The incorporation of sewage sludge may changes the chemical, physical and biological soil properties, for being rich in macro and micronutrients and organic matter. These changes can provide benefits such as the increase in the availability of nutrients for plants, and the induction of suppressiveness to soilborne plant pathogens and resistance to foliar diseases. However, it may influence negatively the biological and chemical balance of the soil, due to the presence of contaminants. The objective of this work was to evaluate the effect of sewage sludge on the severity soybean (Glycine max) powdery mildew (Erysiphe diffusa) and on suppressiveness to Rhizoctonia solani and Macrophomina phaseolina The experiments used soil which received four successive applications of sewage sludge (from 1999 to 2001), originally from the wastewater treatment station of Barueri and Franca counties, São Paulo State, Brazil, in concentrations of $0,1,2,4$ and 8 times $(0 \mathrm{~N}$ to $8 \mathrm{~N})$ the dose of $\mathrm{N}$ recommended for corn. Two experiments were conducted to investigate the effects of sewage sludge on soybean powdery mildew (E. diffusa) in a naturally infested greenhouse. In another experiments, the soybean emergency and powdery mildew severity were evaluated in plants growing in container media mixed with $0 ; 2.5 ; 5 ; 10 ; 15$ and $20 \%$ of sewage sludge from Franca Sewage Treatment Station. A similar experiment was conducted twice to evaluate the effects of sewage sludge on seedling emergence, damping-off incidence, and severity of $R$. solani and $M$. phaseolina. In this case, the soil was artificially infested with the pathogens. Sewage sludge incremented elicitation of phytoalexins in soybean and the severity of powdery mildew was reduced with an increase in the concentration of sludge in the soil and 
substrate. Seedling emergence, in the three cropping periods, was inversely proportional to the Franca sewage sludge concentrations, at $20 \%$ totally inhibited the soybean seedling emergence. Franca sewage sludge not affects damping-off and severity caused by $R$. solani. For Barueri sludge, in the first cropping, there was a quadratic response for damping-off, with increased of $1 \mathrm{~N}$ and $2 \mathrm{~N}$, and reduction at $4 \mathrm{~N}$. In the second cropping, increased damping-off, but a quadratic response with an inflection point at $1 \mathrm{~N}$. On the other land, the damping-off was the same for control and $8 \mathrm{~N}$. For severity, in two soybean cropping, Barueri sludge presents a quadratic response with an inflection point at $4 \mathrm{~N}$. The incidence of $M$. phaseolina was inversely proportional to Franca sewage sludge concentration. In the present study, there were no treatment affects the suppressiveness of $R$. solani and M. phaseolina.

Keywords: Organic residues, soybean diseases, suppressiveness, microbial activity, Rhizoctonia solani, Macrophomina phaseolina

O lodo de esgoto é um resíduo gerado nas Estações de Tratamento de Esgoto (ETEs), tendo em sua composição macro e micronutrientes essenciais para as plantas e matéria orgânica, que necessita de uma adequada disposição final. A utilização do lodo esgoto na agricultura brasileira cresce anualmente, pois dentre as alternativas de disposição é a que apresenta o menor custo (5). O CONAMA (Conselho Nacional de Meio Ambiente) (11) estabeleceu critérios e limites aceitáveis de contaminantes químicos e biológicos para a disposição agrícola do lodo de esgoto. A aplicação do lodo de esgoto interfere nas propriedades físicas, químicas e biológicas do solo, dentre elas as relacionadas com as doenças de plantas, podendo estimular a supressividade aos patógenos veiculados pelo solo $(6,8,18,22,23,26,33,38)$. Nesse sentido, a incorporação de lodo de esgoto nos solos reduziu a incidência ou a severidade do mofo-branco em alface, causado por Sclerotinia minor (Lib.) de Bary $(27,28)$; das podridões de raízes de sorgo e de cana-de-açúcar, causadas por Pythium arrhenomanes Drechsler (4, 14); da podridão do colo do pimentão, causada por Phytophthora capsici Leonian (26); do tombamento causado por Rhizoctonia solani Kühn e Pythium ultimum Trow em ervilha e algodão (24); da podridão de raiz em feijão, algodão e rabanete, causada por Rhizoctonia solani (26); do tombamento e da podridão do colo de feijoeiro, causadas por Sclerotium rolfsii Sacc. (33) e de podridão de Ralstonia solanacearum em tomate (18) Por outro lado, Kim et al. (20) relataram que o lodo de esgoto não interferiu na incidência das podridões de raízes e do colo, causadas por Phytophthora capsici, em pimenta, nem reduziu a população do patógeno no solo. Encontrando-se também relatos de aumento de doenças com a incorporação do lodo de esgoto, como a podridão do colmo do milho, causado por Fusarium (3) e podridões radiculares causadas por P. ultimum e Thielaviopsis basicola (Berk \& Broome) Ferraris, em feijão, ervilha e algodão (28). O modo pelo qual o lodo de esgoto reduz a severidade das doenças está relacionado com $\mathrm{o}$ aumento da atividade microbiana no solo e à própria microbiota contida no material orgânico $(14,18,33)$.

As plantas, após a exposição a agentes bióticos ou abióticos, podem ser induzidas à defesa contra patógenos, enquanto permaneçam espacialmente separados, sem exibirem alterações, o que é conhecido como resistência sistêmica induzida (31). O uso de composto orgânico no solo induziu resistência em pepino à antracnose, porém o mecanismo permanece desconhecido (38). Sabe-se que fatores químicos ou biológicos, relacionados à matéria orgânica, podem induzir este efeito nas plantas (25). No tocante a indução de resistência pela adição do lodo de esgoto no solo destaca-se efeitos advindos da presença de microrganismos como também de compostos inorgânicos, incluindo metais pesados (21). Contudo, há necessidade de se estudar os efeitos do lodo de esgoto como possível promotor da indução de resistência em plantas.

No Brasil poucos estudos foram conduzidos para avaliar o efeito do lodo de esgoto na indução de supressividade a patógenos do solo e de resistência a patógenos foliares. Entre estes estudos pode-se destacar a contribuição de Ghini et al. (18) que investigaram efeitos do lodo na supressividade de diferentes patógenos de solo que recebeu aplicação de lodo de esgoto durante seis anos. Salientando que a avaliação do impacto ambiental causado no agroecossistema é importante para a seleção de culturas que podem ser beneficiadas com a aplicação do lodo.

Em função da importância econômica da soja para o país e do potencial que representa o lodo de esgoto como fonte de carbono e nutrientes, bem como no seu potencial efeito sobre doenças em plantas, foi desenvolvido o presente trabalho para avaliação do efeito de doses e tipos de lodo de esgoto incorporado ao solo sobre a severidade de oídio (Erysiphe diffusa), eliciação de fitoalexinas, e na indução de supressividade a Rhizoctonia solani e Macrophomina phaseolina em soja.

\section{MATERIAL E MÉTODOS}

O solo utilizado foi obtido de um experimento conduzido no Campo Experimental da Embrapa Meio Ambiente, localizado em Jaguariúna (SP), em Latossolo Vermelho Distroférrico (textura argilosa), cujas características físicas e químicas na camada de $0-20 \mathrm{~cm}$, antes do início do estudo foram as seguintes: $\mathrm{pH}$ em água=5,8; $\mathrm{MO}=25,5 \mathrm{~g} \mathrm{~kg}^{-1}$; $\mathrm{P}=3,5 \mathrm{mg} \mathrm{dm}^{-3} ; \mathrm{K}=1,51 ; \mathrm{Ca}=27,5 ; \mathrm{Mg}=8,5 ; \mathrm{Al}=1 ; \mathrm{H}=35 ; \mathrm{CTC}=73,5$ mmolc dm ${ }^{-3} ; \mathrm{V} \%=50,8 ;$ e argila $=450 \mathrm{~g} \mathrm{~kg}^{-1}$. Os lodos de esgotos, cujas características estão apresentadas em Bettiol et al. (7), foram obtidos nas Estações de Tratamento de Esgoto de Barueri e de Franca, SP. As informações sobre a condução do experimento, bem como as variedades cultivadas e as datas de semeadura estão apresentadas em Bettiol et al. (7). Os tratamentos, para cada lodo, foram: testemunha absoluta; lodo de esgoto com base na concentração de nitrogênio para fornecer a mesma quantidade de $\mathrm{N}$ da fertilização mineral (1N); e duas $(2 \mathrm{~N})$, quatro (4N) e oito (8N) vezes a quantidade de $\mathrm{N}$ fornecida pelo lodo de esgoto. Os cálculos das doses de lodo foram realizados em função do nitrogênio disponível para as plantas, considerando a taxa de mineralização do nitrogênio. Para os tratamentos com lodo, quando necessária, foi realizada complementação com potássio. O lodo foi incorporado anualmente em quatro aplicações, desde 1999 (abril e dezembro de 1999, outubro de 2000 e novembro de 2001). Os lodos foram distribuídos a lanço, na área total das parcelas experimentais, e incorporados a $20 \mathrm{~cm}$ de profundidade com auxílio de enxada rotativa, três a quatro dias antes da semeadura. Para avaliação do efeito do lodo de esgoto sobre os patógenos estudados neste trabalho foram coletadas amostras de solo em março de 2002, após a quarta aplicação de lodo na área experimental. As amostras, em média pesando $10 \mathrm{~kg}$, foram retiradas de cinco pontos, na profundidade de $0-20 \mathrm{~cm}$, de cada parcela do experimento descrito anteriormente. Logo após foram homogeneizadas e peneiradas para realização dos experimentos com os patógenos em casa de vegetação, os quais foram conduzidos entre abril e dezembro de 2002. O delineamento experimental utilizado foi 
inteiramente casualizado. Sendo cada parcela do campo experimental sub-dividida em duas sub-parcelas, totalizando no final seis repetições.

Efeito do lodo de esgoto sobre a severidade de oídio (E. diffusa) da soja e eliciação de fitoalexinas. Para a avaliação do efeito do lodo de esgoto sobre a severidade de oídio na soja foram conduzidos dois experimentos. O solo coletado da área experimental foi distribuído em vasos ( $2 \mathrm{~kg}$ de solo por vaso). O primeiro experimento foi conduzido durante os meses de março e abril e o segundo nos meses de maio e junho, utilizando-se os mesmos vasos com solo utilizado no primeiro experimento. No primeiro experimento, foram semeadas cinco sementes de soja (BRS 133) por vaso, sendo que após a emergência foram conduzidas duas plantas por vaso. Nas laterais do experimento foram dispostos 20 vasos contendo plantas de soja, de dois meses de idade, infectadas com oídio, as quais foram utilizadas como fonte natural de inóculo. O experimento foi conduzido por 50 dias. Após este período as plantas foram coletadas e realizada nova semeadura para a condução do segundo experimento nas mesmas condições descritas anteriormente. A avaliação da severidade de oídio foi realizada 50 dias após a semeadura, por meio de escala de notas de 0 a 5 conforme descrito por Yorinori (37), a qual foi baseada na quantificação do nível de infecção da área foliar infectada (AFI): $0=$ sem sintoma ou sinal visível; $1=$ traços a $10 \%$ de AFI; $2=11 \%$ a $25 \%$ da AFI; $3=26 \%$ a $50 \%$ da AFI; $4=51 \%$ a $75 \%$ da AFI; e $5=75 \%$ a $100 \%$ da AFI.

$\mathrm{Na}$ investigação do efeito do lodo de esgoto na eliciação de fitoalexinas foi realizado um experimento utilizando-se cotilédones de soja (36) da variedade BRS 133 que foram destacados de plântulas com nove dias de idade, cultivadas nos vasos contendo os solos coletado na área experimental. Os cotilédones foram lavados com água bidestilada esterilizada e enxugados suavemente com papel absorvente fino. Para avaliação do acúmulo de fitoalexinas, os cotilédones foram pesados e colocados em metanol $80 \%$, acidificado com $\mathrm{HCl}$ a $0,1 \%$ (v/ v). Para a extração do complexo de pigmentos, nos quais estariam presente as fitoalexinas foi mantida a proporção 1:50 entre massa de cotilédone fresco $(\mathrm{g})$ e volume de metanol $(\mathrm{mL})$. Os cotilédones foram mantidos a $4^{\circ} \mathrm{C}$ no metanol por um período de $96 \mathrm{~h}$, para permitir a completa extração do complexo de pigmentos, o qual foi avaliado a $480 \mathrm{~nm}$, sendo os dados expressos em A $480 \mathrm{~nm}$ por grama de cotilédone fresco $\left(\mathrm{A}_{480 \mathrm{~nm}} \mathrm{gcf}^{-1}\right)$.

Com a finalidade de avaliar o efeito de concentrações maiores de lodo no solo sobre a severidade do oídio, outros dois experimentos foram conduzidos em casa de vegetação utilizando-se o lodo de esgoto proveniente da ETE de Franca, SP. O lodo de esgoto seco foi misturado ao solo obtido de área sob cultivo de pastagens em Presidente Prudente, SP, nas concentrações $(\mathrm{p} / \mathrm{p})$ de $0 \% ; 2,5 \% ; 5,0 \% ; 10,0 \% ; 15,0 \%$ e $20,0 \%$. O substrato obtido foi acondicionado em vasos plásticos (2 $\mathrm{kg}$ ) e foram semeadas 20 sementes de soja (BRS 133), que após a emergência foram conduzidas em duas plantas por vaso. O primeiro experimento foi conduzido por 50 dias, durante os meses de abril e maio de 2002. O segundo experimento foi conduzido nos mesmos vasos, após a coleta das plantas do primeiro, durante os meses de maio a junho de 2002, seguindo-se a mesma metodologia do primeiro. A avaliação da severidade de oídio, em ambos os experimentos, foi realizada de acordo com Yorinori (37) aos 21 e 35 dias após a semeadura. Paralelamente à avaliação da severidade de oídio foi avaliado o efeito do lodo de esgoto da ETE de Franca na emergência de plântulas de soja em três cultivos. As duas primeiras avaliações foram realizadas nos experimentos descritos acima, e a terceira avaliação realizada nos mesmos substratos contidos nos vasos, seguindo o mesmo procedimento de semeadura, exclusivamente para avaliação de emergência. $O$ delineamento experimental foi inteiramente casualizado com seis repetições.

Efeito do lodo de esgoto na indução de supressividade à $\boldsymbol{R}$. solani da soja. Com a finalidade de avaliação do efeito do lodo de esgoto na indução de supressividade à $R$. solani, foram realizados dois experimentos consecutivos em casa de vegetação. $\mathrm{O}$ solo coletado no experimento de campo foi distribuído em vasos contendo $2 \mathrm{~kg}$ de solo. Para infestação do solo utilizou-se um isolado de $R$. solani, AG-4 HGI, cedido pelo Dr. Nilton L. Souza, UNESP, Botucatu, SP, sendo previamente preparado em substrato areno-orgânico, incorporado ao solo com a adição do inóculo na proporção de $1 \%$ (p/p). Em seguida, nos solos infestado e não infestado, foram semeadas dez sementes por vaso de soja cv. Conquista, sendo que após avaliação de emergência foram mantidas duas plantas por vaso. O experimento foi conduzido por 30 dias, sendo avaliadas: 1) tombamento de pré-emergência (estimado pela diferença entre as porcentagens de germinação nos tratamentos não infestados e seus correspondentes infestados); 2) severidade nas plantas com lesão no colo por meio de escala de notas de 0 a 5 ( $0=$ colo saudável e $5=$ colo totalmente lesionado), adaptado de Lumsden et al. (26). Somente foram consideradas as lesões típicas de sintoma de $R$. solani, caracterizadas por coloração pardo-avermelhada, deprimidas e alongadas no sentido do comprimento do caule (37). Após a coleta do primeiro experimento foi repetido o experimento nos mesmos vasos, seguindo a mesma metodologia e avaliações.

Efeito do lodo de esgoto na indução de supressividade à $M$. phaseolina da soja. Para avaliação de supressividade foi realizado um experimento em casa de vegetação, sendo o solo coletado no experimento de campo distribuído em vasos com capacidade para 2 $\mathrm{kg}$. Para infestação do solo foi utilizada como fonte de inóculo $1,0 \mathrm{~g}$ do pó contendo micélio e microescleródios de $M$. phaesolina, isolado 134, (1×10 ufc/g), cedido pelo Dr. Álvaro M. R. Almeida, da Embrapa Soja, Londrina, PR. O inóculo foi bem misturado ao solo, de cada vaso, utilizando-se um saco plástico para homogeneizar a mistura. Em seguida o solo infestado foi semeado com 10 sementes de soja cv. Conquista, mantendo-se após a emergência duas plantas por vaso. Aos 45 dias após a semeadura as plantas foram retiradas dos vasos e as raízes separadas da parte aérea para avaliação da incidência de $M$. phaseolina. As raízes foram lavadas e secas à temperatura ambiente. De cada raiz, retirou-se, aleatoriamente, quatro fragmentos $(2 \mathrm{~cm})$, os quais foram desinfestados em $0,5 \%$ de hipoclorito de sódio por 1 min., lavados em água esterilizada, e dispostos em placas, com meio BDA, contendo $0,1 \mathrm{~g} / \mathrm{L}$ de sulfato de estreptomicina. As placas foram mantidas a $26^{\circ} \mathrm{C} \pm 2$, no escuro, sendo a avaliação realizada após sete dias. A porcentagem de raízes infectadas foi utilizada para determinação da incidência da doença (1).

Análise estatística. Foi utilizado o programa estatístico Sanest para realização das análises de variância e de regressão $(\mathrm{p}<0,05)$. Modelos lineares ou quadráticos foram utilizados para descrever o efeito das doses de lodo sobre as variáveis estudadas. Em cada caso foram selecionados modelos adequados com coeficientes de correlação significativos.

\section{RESULTADOS E DISCUSSÃO}

Efeito do lodo de esgoto sobre a severidade de oídio da soja e eliciação de fitoalexinas. A incorporação de doses crescentes de lodo de esgoto ao solo ou em substrato reduziu a severidade de oídio em soja. A redução na severidade foi observada no primeiro 
experimento com o aumento das doses de lodo de esgoto no solo até $4 \mathrm{~N}$ para os dois lodos avaliados (Figura 1A). No segundo experimento, realizado sob condições climáticas mais favoráveis a incidência da doença, observou-se que a redução da severidade foi menos acentuada em todos os tratamentos, contudo os tratamentos com lodo na dose $4 \mathrm{~N}$ continuaram apresentando os menores índices de severidade de oídio (Figura 1B). Os resultados encontrados na redução da severidade de oídio estão de acordo com o observado por Zhang et al. (38) em estudos que demonstraram que as doenças foliares são afetadas por compostos orgânicos incorporados ao solo. Dittmer et al. (1990), citados por Trankner (35), avaliando a incidência de oídio em trigo, cultivado em solo que recebeu composto orgânico, observaram redução de $95 \%$ na severidade da doença quando se utilizou partes iguais de solo e composto para desenvolvimento da cultura.

A atividade elicitora de fitoalexinas em cotilédones de soja foi diretamente proporcional à concentração dos lodos de esgoto (Figura 2), demonstrando que as plantas foram estimuladas para aumentar a
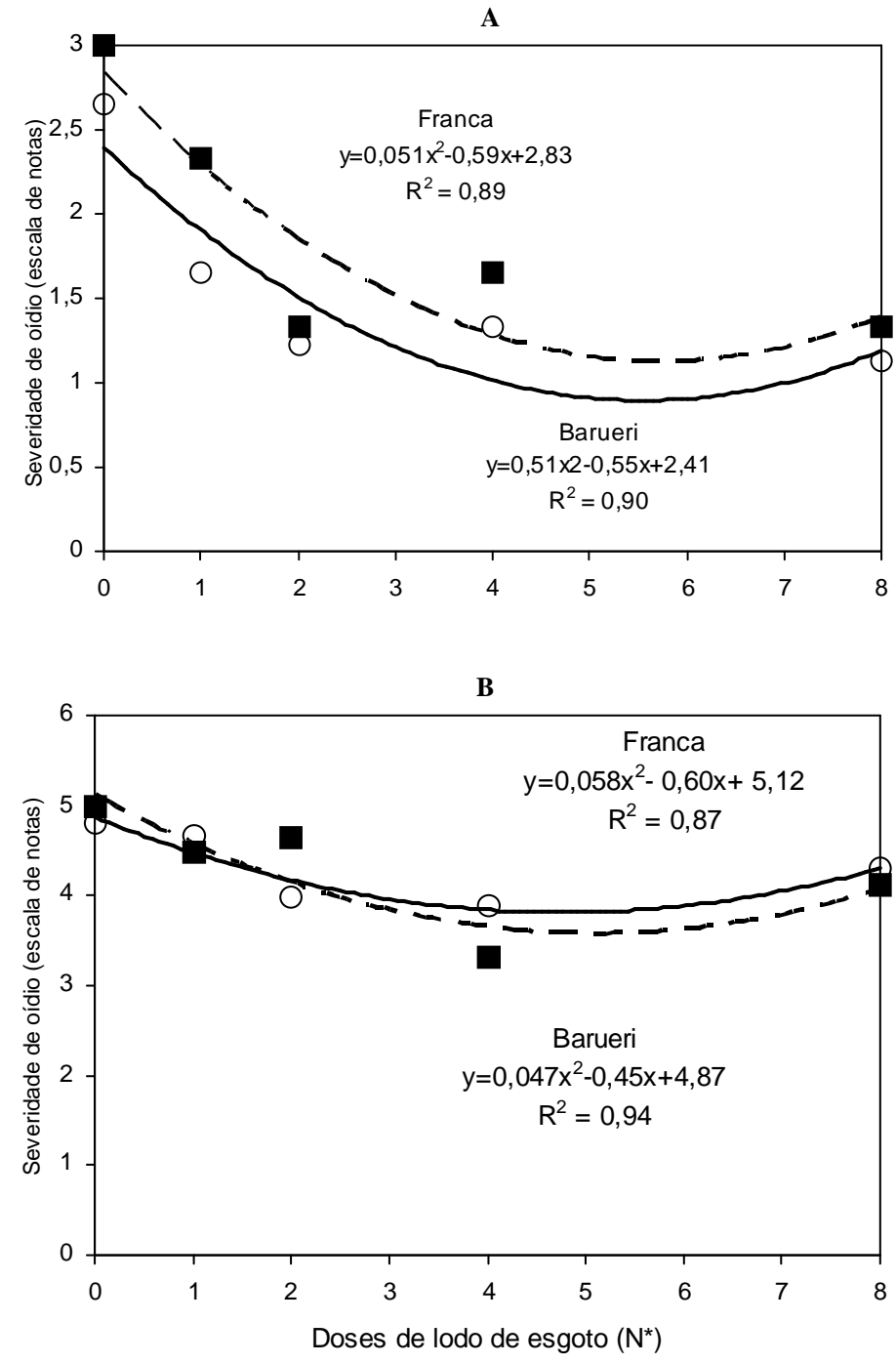

Figura 1. Efeito de lodo de esgoto de Franca ( $\mathbf{0}_{\left.---_{-}\right)}$e Barueri ( $\mathrm{O}_{-}$) na severidade de oídio (Erysiphe diffusa) em soja em dois experimentos consecutivos (A e B) avaliada 50 dias após a semeadura. ${ }^{*} 0 \mathrm{~N}, 1 \mathrm{~N}, 2 \mathrm{~N}, 4 \mathrm{~N}$ e $8 \mathrm{~N}=$ concentrações de lodo necessárias para fornecer zero, uma, duas, quatro e oito vezes a quantidade de $\mathrm{N}$ da adubação mineral recomendada para a cultura de milho. Escala de notas de $0=$ sem sintomas a $5=75$ a $100 \%$ da área foliar infectada.

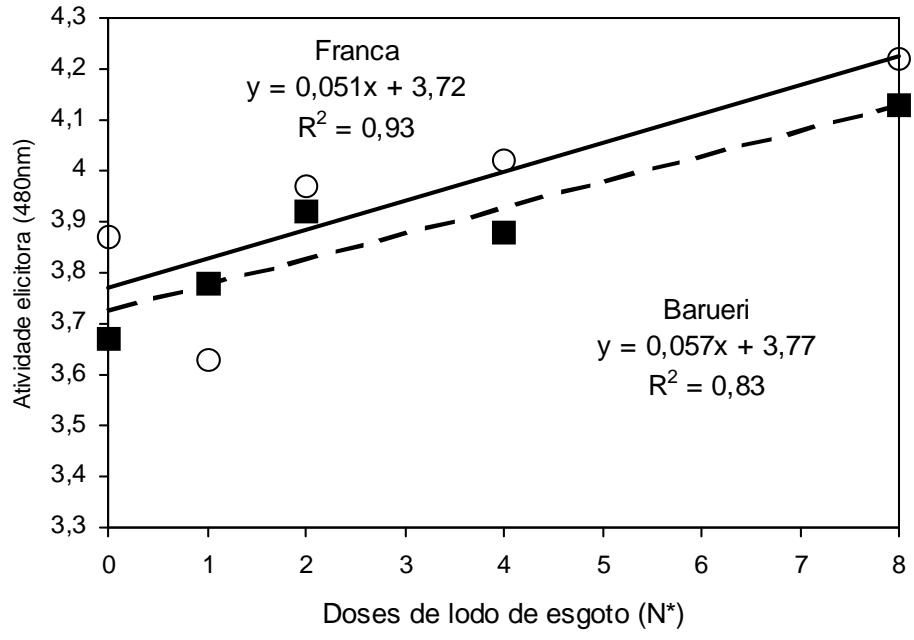

Figura 2. Efeito de lodo de esgoto de Franca ( $\mathbf{- - - -}_{--}$) e Barueri $(\mathrm{O}-)$ na atividade eliciadora de fitoalexinas em cotilédones de soja CV BRS133 com nove dias de idade. ${ }^{*} 0 \mathrm{~N}, 1 \mathrm{~N}, 2 \mathrm{~N}, 4 \mathrm{~N}$ e $8 \mathrm{~N}=$ concentrações de lodo necessárias para fornecer zero, uma, duas, quatro e oito vezes a quantidade de $\mathrm{N}$ da adubação mineral recomendada para a cultura de milho.

atividade no metabolismo de defesa. $\mathrm{O}$ aumento na atividade elicitora de fitoalexinas e a redução da severidade de oídio nas plantas cultivadas em solo que recebeu lodo de esgoto sugerem que o fenômeno de controle de doenças, encontrado neste trabalho, possa ser indução de resistência $(21,29,31)$. A indução de resistência ao oídio pode ter sido proporcionada por algum agente de natureza química ou biológica presentes no lodo ou pelo estimulo da atividade microbiana do solo, conforme observada por Fernandes et al. (17) nos mesmos tratamentos.

Nos experimentos utilizando-se doses crescentes de lodo de esgoto da ETE Franca verificou-se que a emergência das plântulas e a severidade do oídio foram inversamente proporcionais à concentração de lodo de esgoto (Figuras 3 e 4). Nas concentrações acima de 2,5\% de lodo houve reduções significativas da severidade da doença avaliadas aos 21 e 35 dias após a semeadura (Figura 3). Esses dados estão de acordo com os obtidos por Zhang et al. (38) e Dittmer et al. (1990) citados por Trankner (35). Entretanto, a emergência de plântulas de soja foi reduzida em concentrações superiores a 5\% (Figura 4). No tratamento que recebeu $20 \%$ de lodo de esgoto não foi possível avaliar o efeito sobre a doença, pois não ocorreu emergência das plântulas no primeiro e no segundo cultivos. Problemas de fitotoxicidade em plantas de feijão cultivadas em substrato e solo contendo lodo de esgoto também foram relatados por Santos \& Bettiol $(32,33)$. Dessa forma, é importante considerar a aplicação de quantidades corretas de lodo de esgoto ao solo. Além disso, é importante considerar que o lodo de esgoto deve ser aplicado ao solo na dosagem recomendada segundo a norma do CONAMA (11).

Seria interessante realizar estudos sobre o efeito de lodo de esgoto na severidade de oídio da soja numa área de cultivo comercial para a confirmação dos resultados de casa de vegetação com alto potencial de inóculo.

Efeito do lodo de esgoto na indução de supressividade à $R$. solani e M. phaseolina da soja. Não foi observado efeito da aplicação do lodo da ETE de Franca sobre a doença causada por $R$. solani (Figuras 5 e 6). Para os dois cultivos, o tombamento e a severidade não apresentaram uma resposta clara. Entretanto, no primeiro cultivo a resposta quanto ao tombamento para o lodo de Barueri foi quadrática, 

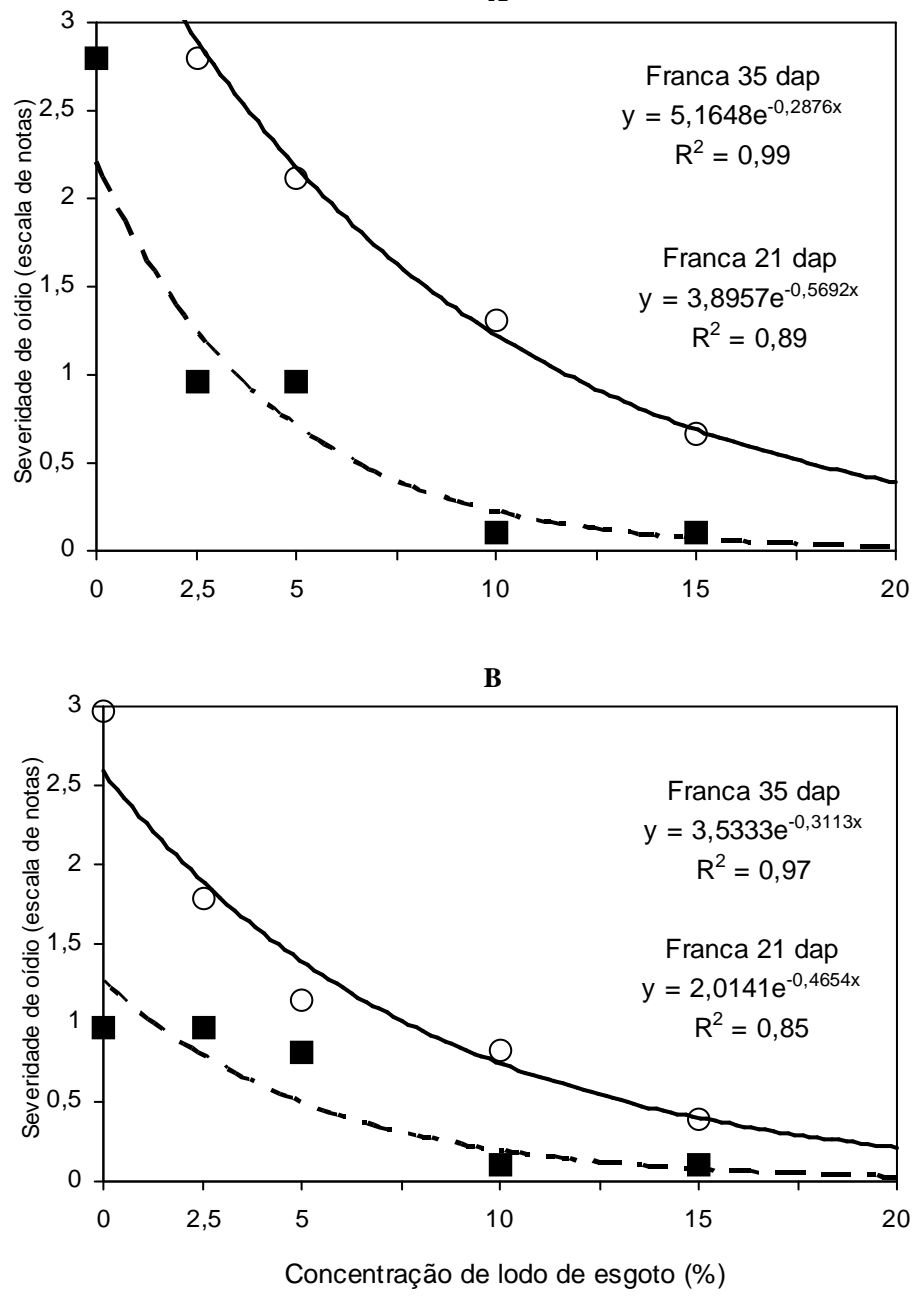

Figura 3. Efeito de concentrações $(0 ; 2,5 ; 5 ; 10 ; 15$ e $20 \%$ v/v) de lodo de esgoto da ETE de Franca na severidade de oídio (Erysiphe diffusa) em soja aos 21 ( ----) e 35 ( $Q-$ ) dias após a semeadura em dois experimentos consecutivos (A e B). *Não houve emergência de plantas no tratamento $20 \%$ de lodo. Escala de notas de $0=$ sem sintomas a $5=75$ a $100 \%$ da área foliar infectada.

sendo que ocorreu aumento nas concentrações de $1 \mathrm{~N}$ e $2 \mathrm{~N}$, e redução na concentração 4N (Figura 5A). No segundo cultivo ocorreu aumento nos índices de tombamento de plantas em relação ao primeiro, com resposta quadrática para o lodo Barueri, mas com ponto de inflexão mínimo na concentração de $1 \mathrm{~N}$, sendo que para a maior concentração o tombamento foi semelhante à testemunha (Figura 6A). A severidade da doença no colo das plantas manteve a mesma resposta quadrática para o lodo de Barueri nos dois cultivos (Figuras 5B e 6B), com ponto de máximo na dose $4 \mathrm{~N}$. O tombamento e a severidade para a concentração $8 \mathrm{~N}$ foram semelhantes à testemunha (Figuras 5 e 6). Ghini et al. (18) avaliando solos onde foram aplicados doses de lodos de esgoto de Franca e Barueri encontraram variação considerável na influência dos mesmos na supressividade a $R$. solani. Vários fatores bióticos e abióticos têm efeito na supressividade de solos a $R$. solani $(9,30)$. Dentre estes fatores, alguns estão relacionados à relação $\mathrm{C}: \mathrm{N}$ e ao processo de decomposição do carbono adicionado ao solo (16). Lumsden et al. (26) verificaram que o lodo de esgoto compostado, com relação C:N mais alta, estimulou o aumento de supressividade a $R$. solani. Neste trabalho utilizando lodo de esgoto com relação C:N mais baixa não foi verificada redução de severidade da doença. É

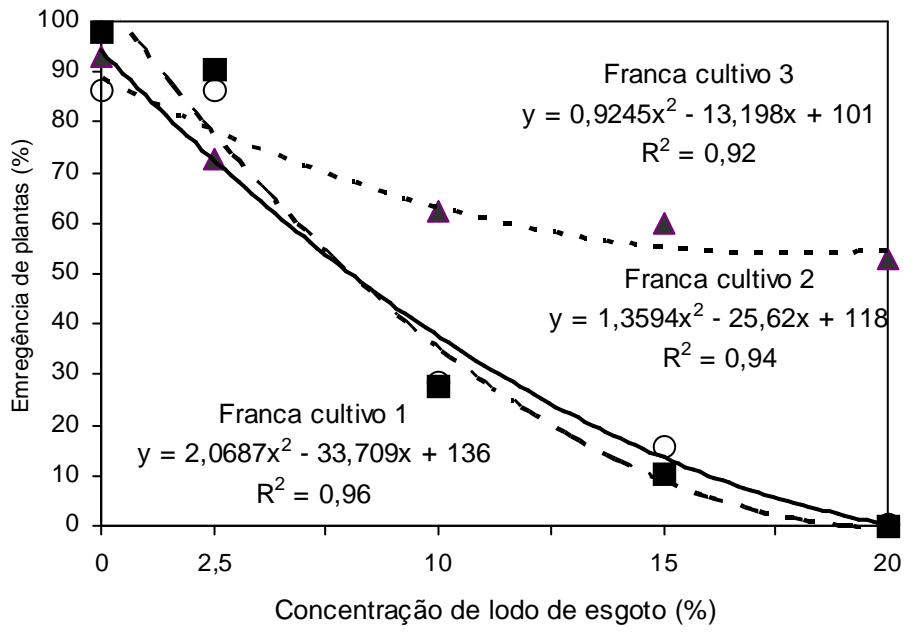

Figura 4. Efeito de concentrações de lodo $(0 ; 2,5 ; 5 ; 10 ; 15$ e $20 \%$ v/v) de esgoto da ETE de Franca na emergência de soja no primeiro ( $\mathbf{0}_{--}$), segundo ( $\bigcirc-$ ) e terceiro $(\boldsymbol{\Delta}$.......) cultivos em casa de vegetação.

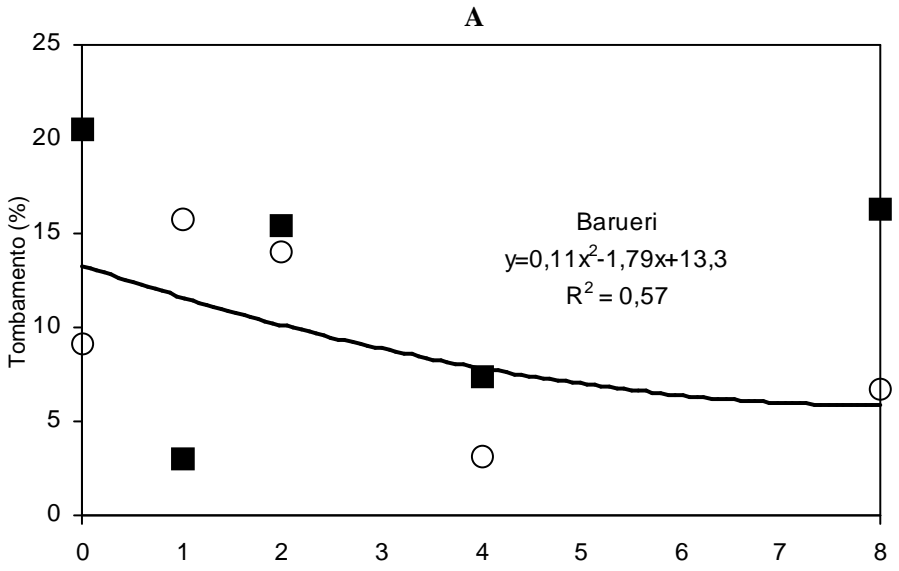

B

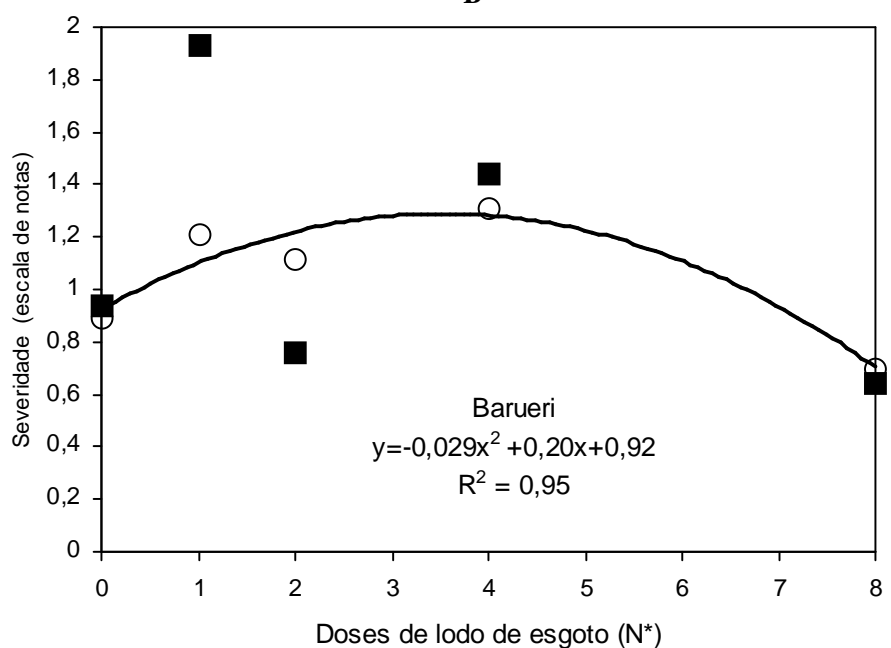

Figura 5. Efeito de concentrações de lodo de esgoto de Franca $\square$-- -) e Barueri $(\mathrm{O}-$ ) no tombamento (A) e severidade (B) de Rhizoctonia solani em soja cv Conquista (Primeiro cultivo). ${ }^{*} 0 \mathrm{~N}, 1 \mathrm{~N}, 2 \mathrm{~N}, 4 \mathrm{~N}$ e $8 \mathrm{~N}=\mathrm{doses}$ de lodo necessárias para fornecer uma, duas, quatro e oito vezes a quantidade de $\mathrm{N}$ da adubação mineral para a cultura de milho. Escala de notas $(0=$ colo saudável e $5=$ colo totalmente lesionado. 


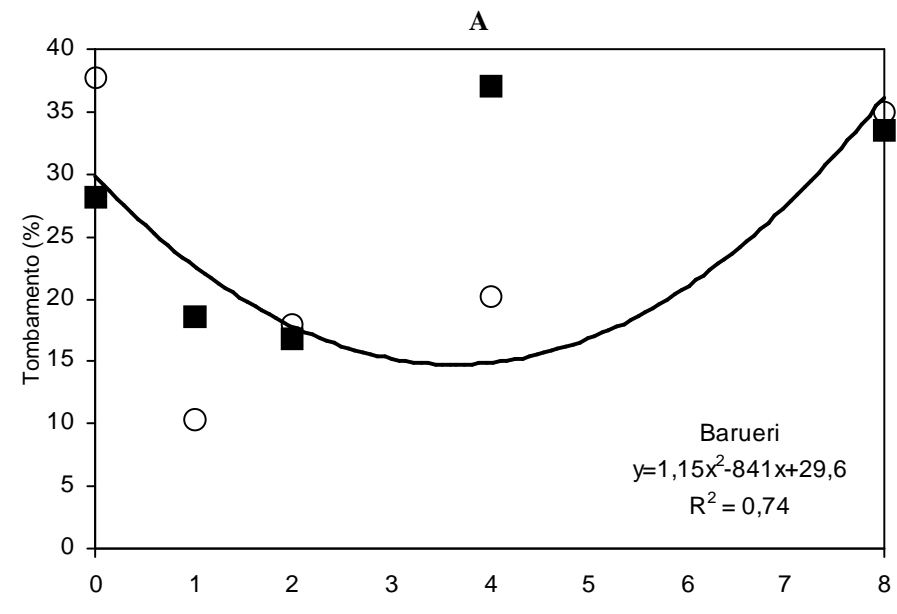

B

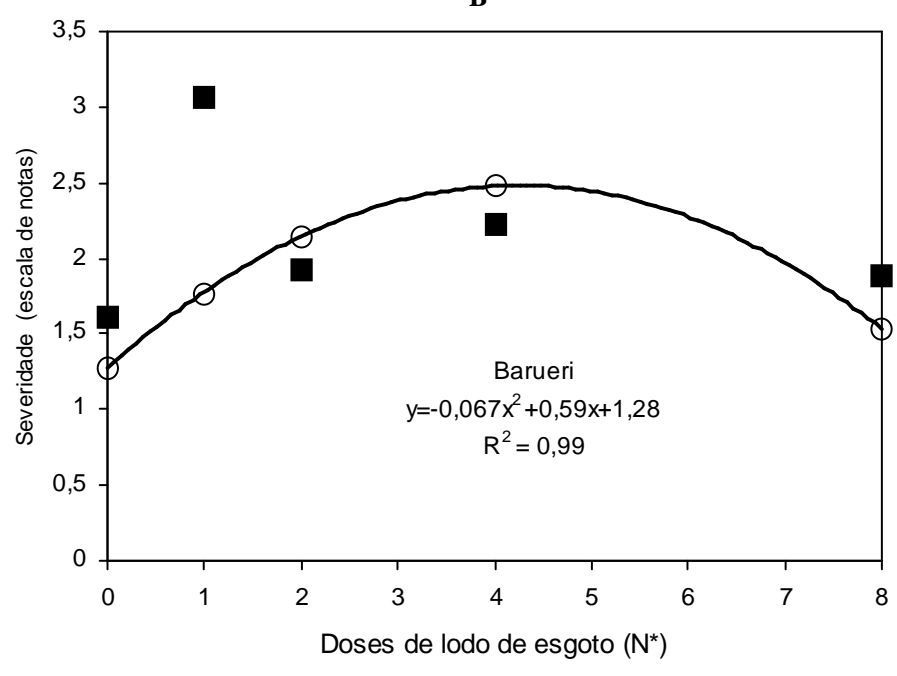

Figura 6. Efeito de lodo de esgoto de Franca - --) e Barueri ( $\mathrm{O}-$ ) no tombamento (A) e severidade (B) de Rhizoctonia solani em soja cv. Conquista (Segundo cultivo). $* 0 \mathrm{~N}, 1 \mathrm{~N}, 2 \mathrm{~N}, 4 \mathrm{~N}$ e $8 \mathrm{~N}=$ concentrações de lodo necessárias para fornecer uma, duas, quatro e oito vezes a quantidade de $\mathrm{N}$ da adubação mineral recomendada para a cultura de milho. Escala de notas $(0=$ colo saudável e $5=$ colo totalmente lesionado.

importante considerar que a supressividade do lodo a $R$. solani depende da planta hospedeira e do tempo entre a aplicação do lodo e os estudos de supressividade (28).

Com relação a $M$. phaseolina observou-se que o lodo de Franca reduziu a incidência do patógeno nas raízes (Figura 7). Contudo, este efeito não foi pronunciado no solo que recebeu lodo de Barueri. Poucos estudos foram feitos para comprovar efeito supressivo em solos que receberam resíduos orgânicos em relação a $M$. phaseolina. Sabe-se que uma das formas de controlar este fungo no solo é interferindo na sua sobrevivência com a promoção de ambiente inadequado para seu desenvolvimento (19). Avaliando a incidência de M. phaseolina em raízes de soja, Almeida et al. (1) constataram maior presença do fungo em plantas cultivadas no sistema convencional quando comparadas ao plantio direto, ficando evidente o efeito do sistema de cultivo. Chun \& Lockwood (10) concluíram que o aumento da concentração de amônia no solo foi efetivo na redução da população de $M$. phaseolina. A liberação de amônia derivada da aplicação de resíduos, com concentração elevada de N, pode esclarecer uma das formas de controle de patógenos

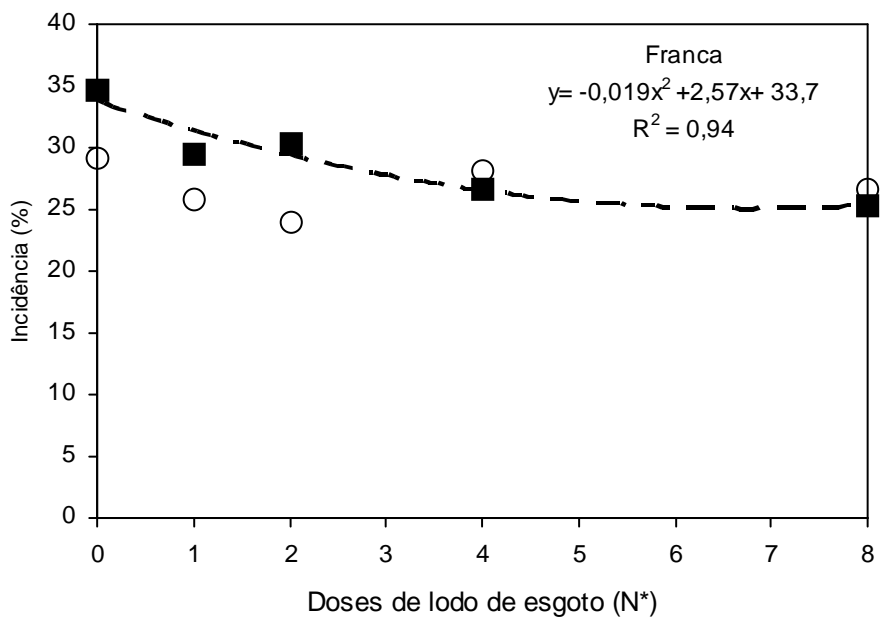

Figura 7. Efeito de lodo de esgoto de Franca $\left(\mathbf{q}_{--}\right)$e Barueri $(\mathrm{O}-)$ na incidência de Macrophomina phaseolina em raízes de soja cv. Conquista aos 45 dias após a semeadura. ${ }^{*} 0 \mathrm{~N}, 1 \mathrm{~N}, 2 \mathrm{~N}, 4 \mathrm{~N}$ e $8 \mathrm{~N}=$ concentrações de lodo necessárias para fornecer uma, duas, quatro e oito vezes a quantidade de $\mathrm{N}$ da adubação mineral recomendada para a cultura de milho.

no solo (2).

Diversos autores correlacionam a atividade microbiana com a supressividade aos patógenos do solo $(3,7,8,12,14,23,24,33)$. No presente trabalho não foi possível realizar essa correlação para $R$. solani, pois apesar de outros estudos na mesma área demonstrarem aumento da atividade microbiana nas maiores doses de lodo de esgoto $(7,13,17)$, os dados de tombamento e severidade apresentaram considerável variação. Resultados conflitantes também foram observados por Ghini et al. (18), os quais verificaram que as respostas à indução de supressividade a $R$. solani foram afetadas pelos métodos utilizados nos estudos e pelo tempo entre a incorporação do lodo e a realização do estudo. Também fatores químicos estão envolvidos com os resultados, como por exemplo, o excesso de $\mathrm{N}$ disponível no solo, observado por Dynia et al. (15) na mesma área. Millner et al. (28) observaram que um substrato produzido com lodo de esgoto controlou o tombamento em diversas culturas em casa de vegetação. Esses mesmos autores verificaram que em campo o lodo foi efetivo em controlar o patógeno em ervilha, mas não em algodão. Muitos dos estudos com resultados positivos do uso de lodo de esgoto para suprimir $R$. solani foram conduzidos em substratos e com taxas de incorporação do lodo muito superiores ao desse estudo.

\section{REFERÊNCIAS BIBLIOGRAFICAS}

1. Almeida, A.M.R.; Torres, E.; Farias, J.R.B.; Benato, L.C.; Pinto, M.C.; Marin, S.R.R. Macrophomina phaseolina em soja: sistema de semeadura, sobrevivência em restos de cultura e diversidade genética.Londrina: Embrapa Soja, 2001. 47p (Circular Técnica/ Embrapa Soja, 34).

2. Bailey, K.L.; Lazarovits, G. Suppressing soil-borne diseases with residue management and organic amendments. Soil and Tillage Research, Amsterdam, v.72, p.169-180, 2003.

3. Bettiol, W. Effect of sewage sludge on the incidence of corn stalk rot caused by Fusarium. Summa Phytopathologica, Botucatu, v. 30, p.16-22, 2003.

4. Bettiol, W.; Krugner, T.L. Influência do lodo de esgoto na severidade da podridão de raiz do sorgo causada por Pythium arrheno- 
manes. Summa Phythopatologica, Piracicaba, v. 10, p.243251, 1984.

5. Bettiol, W.; Camargo, O.A. Lodo de esgoto: impactos ambientais na agricultura. Jaguariúna: Embrapa Meio Ambiente, 2006. 349p.

6. Bettiol, W.; Santos, I. Efeito de lodo de esgoto sobre fitopatógenos veiculados pelo solo: estudos de casos. In: Bettiol, W.; Camargo, O.A. (Ed.) Lodo de esgoto: impactos ambientais na agricultura. Jaguariúna: Embrapa Meio Ambiente. 2006. p.315-347.

7. Bettiol, W.;Camargo, O.A.; Galvão, J.A.H.; Ghini, R. Impacto ambiental do uso agrícola do lodo de esgoto: descrição do estudo. In: Bettiol, W.; Camargo, O.A. (Ed.) Lodo de esgoto: impactos ambientais na agricultura. Jaguariúna: Embrapa Meio Ambiente. 2006. p. 17-23.

8. Chen, W.; Hoitink, H.A.J.; Schmitthenner, A.F. Factors affecting suppression of Pythium damping-off in container media amended with composts. Phytopathology, St. Paul, v. 77, p.755-760, 1987.

9. Chet, I.; Baker, R. Induction of suppressiveness to Rhizoctonia solani in soil. Phytopathology, St Paul, v. 70, p.286-290, 1980.

10. Chun, D.; Lockwood, J.L. Reductions of Pythium ultimum, Thielaviopsis basicola, and Macrophomina phaseolina populations in soil associated with ammonia generated from urea. Plant Disease, St. Paul, v. 69, p.54-158, 1985.

11. Conselho Nacional de Meio Ambiente. Resolução 375/2006 que dispõe sobre uso agrícola de lodo de esgoto. Diário Oficial da União, Brasília, DF, 30 ago. 2006. n.167, seção 1, p.141-146.

12. Craft, C. M.; Nelson, E. B. Microbial properties of composts that suppress damping-off and root rot of creeping bentgrass caused by Pythium graminicola. Applied and Environmental Microbiology, Washington, v. 62, p. 1550-1557, 1996.

13. Dias, B.O.; Silva, C.A.; Soares, E.M.B.; Bettiol, W. Estoque de carbono e quantificação de substâncias húmicas em latossolo submetido a aplicação continua de lodo de esgoto. Revista Brasileira de Ciência do Solo, Viçosa, v. 31, p. 701-711, 2007.

14. Dissanayake, N.; Hoy, J.W. Organic material soil amendment effects on root rot and sugarcane growth and characterization of the materials. Plant Disease, St. Paul, v.83, p.1039-1046, 1999.

15. Dynia, J.F.; Boeira, R.C.; Souza, M.D. Nitrato no perfil de um latossolo vermelho distroférrico cultivado com milho sob aplicações seqüenciais de lodo de esgoto. In: Bettiol, W.; Camargo, O.A. Lodo de esgoto: impactos ambientais na agricultura. Jaguariúna: Embrapa Meio Ambiente, 2006. p. 79-90.

16. Fenille, R.C.; Souza, N.L. Efeitos de materiais orgânicos e da umidade do solo na patogenicidade de Rhizoctonia solani Kuhn GA-e HGI ao feijoeiro. Pesquisa Agropecuária Brasileira, Brasília, v.34, p. 236-241, 1999.

17. Fernandes, S.A.P.; Cerri, C.C.; Bettiol, W. Effect of sewage sludge on microbial activity biomass, basal respiration, metabolic quotient and soil enzymatic activity. Applied Soil Ecology, v.30, p.65-77, 2005.

18. Ghini, R.; Patrício, F.R.A.; Bettiol, W.; Almeida, I.M.G.; Maia, A.H.N. Effect of sewage sludge on suppressiveness to soil-borne plant pathogens. Soil Biology \& Biochemistry, Amsterdam, v. 39, p. 2797-2805, 2007.

19. Kendig, S.R,; Rupe, J.C.; Scott, H.D. Effect of irrigation and soil water stress on densities of Macrophomina phaseolina in soil and roots of two soybean cultivars. Plant Disease, St. Paul, v. 84, p.895-900, 2000.

20. Kim, K.D.; Nemec, S.; Musson, G. Effects of composts and soil amendments on soil microflora and Phytophthora root and crown root of bell pepper. Crop Protection, Surrey, v.16, p.165-
$172,1997$.

21. Kuc, J. Induced systemic resistance - An overview. In: Hammerschmidt, R.; Kuc, J. (Ed.). Induced resistance to disease in plants. The Netherlands: Kluwe A. P., p. 169-175, 1995.

22. Leoni, C.; Ghini, R. Sewage sludge effect on management of Phytophthora nicotianae in citrus. Crop Protection, Surrey, v.25, p. 10-22, 2006.

23. Leoni, C.; Ghini, R. Efeitos do lodo de esgoto na indução de supressividade de solos a Phytophthora nicotianae em citros. In: Bettiol, W. \& Camargo, O.A. Lodo de esgoto: impactos ambientais na agricultura. Jaguariúna: Embrapa Meio Ambiente, 2006. p. 255-290.

24. Lewis, J.A.; Lumsden, R.D.; Millner, P.D.; Keinath, A. Suppression of damping-off of peas and cotton in the field with compost sewage sludge. Crop Protection, Surrey, v.11, p.260-266, 1992.

25. Liu, L.; Hsiang, T.; Carey, K.; Eggens, J.L. Induction of systemic resistance in cucumber against bacterial angular leaf spot by plant growth-promoting rhizobacteria. Phytopathology, St. Paul, v.85, p.843-847, 1995.

26. Lumsden, R.D.; Lewis, J.A.; Millner, P.D. Effect of composted sewage sludge on several soilborne and diseases. Phytopathology, St. Paul, v.73, p.1543-1548, 1983

27. Lumsden, R.D.; Millner, P.D.; Lewis, J.A. Suppression of lettuce drop caused by Sclerotinia minor with composed sewage sludge. Plant Disease, ST. Paul, v.70, p.197-201, 1986.

28. Millner, P. D.; Lumsden, R.D.; Lewis, J.A. Controlling plant disease with sludge compost. Biocycle, Emmaus, v.23, p.50-52, 1982.

29. Pascholati, S. F.; Leite, B. Hospedeiro: Mecanismos de resistência. In: KIMATI et al. Manual de fitopatologia. São Paulo: Ceres. 1995. v.2, p.417-453.

30. Pozzer, I.; Cardoso, J.E. Supressividade natural de um latossolo vemelho-escuro a Rhizoctonia solani. Fitopatologia Brasileira, Brasília, v. 15, p. 206-210, 1990.

31. Romeiro, R.S. PGPR e indução de resistência sistêmica em plantas a patógenos. Summa Phytopathologica, Jaboticabal, v.26, p. $177-184,2000$.

32. Santos, I.; Bettiol, W. Efeito do lodo de esgoto no crescimento micelial de fitopatógenos habitantes do solo e na podridão do colo de plântulas de feijoeiro, causadas por Sclerotium rolfsii, em condições controladas. Revista Ecossistema, Espirito Santo do Pinhal, v. 26, n.2, p.157-161, 2001.

33. Santos, I.; Bettiol, W. Effect of sewage sludge on the rot and seedling damping-off of bean plants caused by Sclerotium rolfsii. Crop Protection, Surrey, v.22, p.1093-1097, 2003.

34. Sneh, B.; Jabali-Hare, S.; Neate, S.; Dust, G. Rhizoctonia species: taxonomy, molecular biology, ecology, pathology and disease control. Dordrechet: Kluwer Academic, 1996. 578p.

35. Trankner, A. Use of agricultural and municipal organic wastes to develop suppressiveness to plant pathogens. In: Tjamos; E.C. et al. (Eds.) Biological control of plant diseases: progress and challenges for the future. New York: Plenum Press, 1992. p.3542 .

36. Wulff, N.A.; Pascholati, S.F. Preparações de Saccharomyces cerevisae elicitoras de fitoalexinas em mesocótilos de sorgo. Scientia Agricola, Piracicaba, v.55, p.138-143, 1998.

37. Yorinori, J.T. Cultivares de soja resistentes a Microsphaera diffusa. Fitopatologia Brasileira, Brasília, v. 22S, p.320-321, 1997.

38. Zhang, W.; Dick, W.A.; Hoitink, H.A.J. Compost-induced systemic acquired resistance in cucumber to Pythium root rot and anthracnose. Phytopathology, St. Paul, v.86, p.1066-1070, 1996. 